\title{
Subarachnoid Hemorrhage Masquerading as Takotsubo Cardiomyopathy
}

Ilia Davarashvili*, Rami Jubeh and Jonathan Balkin

Jesselson Integrated Heart Center, Shaare Zedek Medical Center, Hebrew University of Jerusalem, Jerusalem, Israel

\begin{abstract}
Background: Patients presenting with suspected ST-segment elevation myocardial infarction (STEMI) may have important alternative diagnoses (e.g., aortic dissection, pulmonary emboli) or safety concerns for STEMI management (e.g. head trauma). Subarachnoid hemorrhage (SAH) is a known cause of electrocardiographic and echocardiographic changes that may mimic acute coronary syndromes (ACS) resulting in delay of diagnosis and treatment of the primary disease.
\end{abstract}

Case report: A 50-year-old female patient was admitted with suspected STEMI. She had symptoms of vomiting for three days prior to admission. She had a medical history of schizoaffective disorder, treated with selective serotonin reuptake inhibitors (SSRIs). The electrocardiogram (ECG) on presentation showed sinus rhythm with $3 \mathrm{~mm}$ ST-segment elevation in leads L1, AVL, V2-V5 and reciprocal changes in L3, aVf) Coronary angiography showed normal coronary arteries and Takotsubo Cardiomyopathy was diagnosed. Urgent cranial CT of the head revealed extensive SAH.

Conclusion: Urgent cranial CT should be performed in all patients with neurologic symptoms before cardiac catheterization is performed.

Keywords: Takotsubo cardiomyopathy; Myocardial infarction; Subarachnoid hemorrhage

\section{Introduction}

Subarachnoid hemorrhage (SAH) is a known cause of electrocardiographic and echocardiographic changes that may mimic acute coronary syndromes (ACS) resulting in delay of diagnosis and treatment of the primary disease. Here we report a case of A 50-year-old female patient with suspected STEMI. The electrocardiogram (ECG) showed sinus rhythm with $3 \mathrm{~mm}$ ST-segment elevation in leads L1, AVL, V2-V5 and reciprocal changes in L3, aVf). Coronary angiography showed normal coronary arteries and Takotsubo Cardiomyopathy was diagnosed. Urgent cranial CT of the head revealed extensive SAH.

\section{Case Presentation}

A 50-year-old female was brought directly to the catheterization laboratory by the Emergency Ambulance Service with suspected STEMI. The ECG on presentation showed sinus rhythm with $3 \mathrm{~mm}$ STsegment elevation in leads $\mathrm{L} 1, \mathrm{aVl}, \mathrm{V} 2-\mathrm{V} 5$ and reciprocal ST depression in leads L3, aVf (Figure 1). The paramedics reported that the patient had been to her doctor that morning for vomiting and had been given intravenous fluids. She was treated on the way to the hospital with 5000 Units of intravenous heparin. On arrival the patient was obtunded, with partial response to verbal commands, her pupils were of normal size and responded to light stimulation. Heart rate was 100 beats per minute, blood pressure $145 / 86 \mathrm{mmHg}$, and oxygen saturation $96 \%$ on RA. The remaining physical exam was otherwise unremarkable.

Urgent transradial cardiac catheterization was performed with an additional standard dose of 5000 Units of intravenous heparin. Coronary angiography revealed normal coronary arteries. Urgent echocardiography revealed moderate to severely impaired left ventricular dysfunction with apical ballooning and septal akinesis and a diagnosis of Takotsubo Cardiomyopathy was made (Figure 2) (Videos 1 and 2).

\section{Initial laboratory examination}

Sodium $140 \mathrm{mmol} / \mathrm{L}$, potassium $2.8 \mathrm{mEq} / \mathrm{L}$, chloride $103 \mathrm{mEq} / \mathrm{L}$,



Figure 1: ECG showing ST-segment elevation in leads L1, AVL, V2-V4 and reciprocal changes in L2, L3, AVF.

bicarbonate $24.3 \mathrm{mEq} / \mathrm{L}$, glucose $249 \mathrm{mg} / \mathrm{dL}$, creatinine $0.52 \mathrm{mg} / \mathrm{dL}$, and calcium $9.7 \mathrm{mg} / \mathrm{dL}$. White blood cell count was $18.8 \times 10^{3} / \mathrm{uL}$, hemoglobin $14.7 \mathrm{~g} / \mathrm{dL}$, platelet count $304 \times 10^{3} / \mathrm{uL}$, prothrombin time 28.7 s (INR of 2.34), and partial thromboplastin time failed to clot. Cardiac enzymes revealed a CPK 109 units/L and a troponin T of 1287 $\mathrm{ng} / \mathrm{mL}$ (ref range $0-20$ ).

Additional medical history obtained later from her family revealed complaints of headache for 5 days prior to admission. The patient was transferred to the intensive care unit and an urgent CT of the head

*Corresponding author: Ilia Davarashvili, Jesselson Integrated Heart Center, Moshe dayan 58 app 15, Jerusalem 97570, Israel, Tel: 972548360613; E-mail: idavarashvili@yahoo.com

Received April 03, 2018; Accepted April 19, 2018; Published April 24, 2018

Citation: Davarashvili I, Jubeh R, Balkin J (2018) Subarachnoid Hemorrhage Masquerading as Takotsubo Cardiomyopathy. J Cardiovasc Dis Diagn 6: 320. doi: 10.4172/2329-9517.1000320

Copyright: ( 2018 Davarashvili I, et al.. This is an open-access article distributed under the terms of the Creative Commons Attribution License, which permits unrestricted use, distribution, and reproduction in any medium, provided the original author and source are credited. 
was ordered. Several minutes after arrival in the CCU the patient lost consciousness, stopped breathing and her pupils dilated. Endotracheal intubation was performed immediately followed by emergency CT which showed extensive SAH with signs of herniation and the patient was transferred to the operating theatre where external ventricular drainage was performed (Figure 3).

After several days partial and temporary neurologic improvement occurred, and the patient was transferred to the ward but this was followed by gradual deterioration in her condition, secondary infection with sepsis and the patient died 27 days after admission.
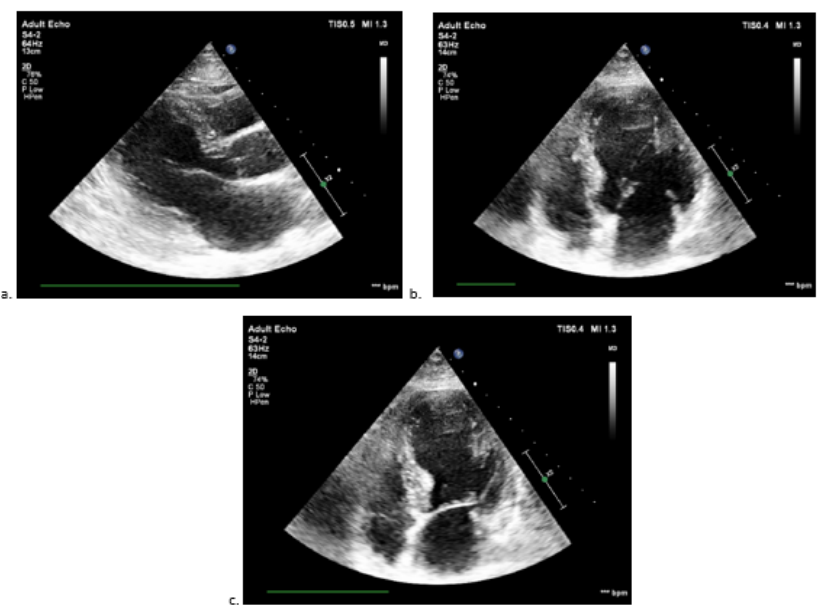

Figure 2: Echocardiography showing moderate to severely left ventricular dysfunction with apical ballooning consistent with Takotsubo Cardiomyopathy: a. parasternal view, b. four-chamber view in diastole, c. four-chamber view in systole.

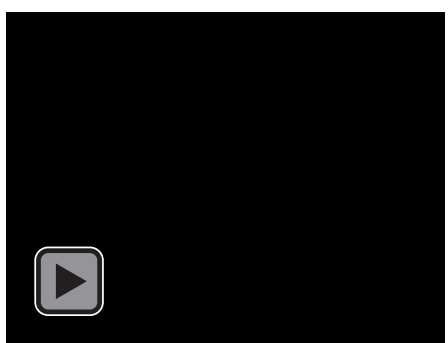

Video 1: Echocardiography showing moderate to severely left ventricular dysfunction with apical ballooning consistent with Takotsubo Cardiomyopathy a. parasternal view (video).

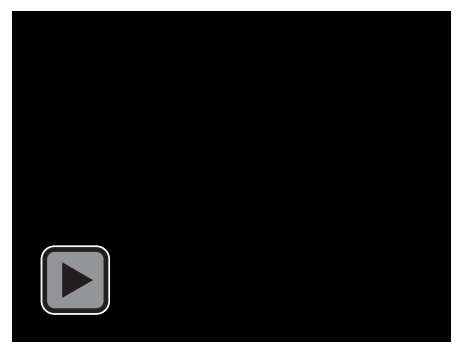

Video 2: Echocardiography showing moderate to severely left ventricular dysfunction with apical ballooning consistent with Takotsubo Cardiomyopathy b. four-chamber view (video)
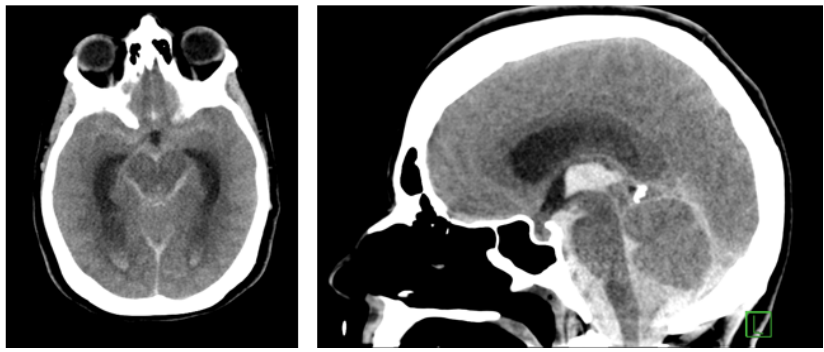

Figure 3: A non-enhanced computed tomography scan of the brain (axial and sagittal sections) demonstrating an extensive subarachnoid hemorrhage $(\mathrm{SAH})$ filling the basilar cisterns with intraventricular extension and early hydrocephalus.

\section{Discussion}

A wide range of ECG abnormalities may be associated with the presentation of SAH, along with elevation in troponin [1-3]. It has been reported that $61.9 \%$ of patients with SAH will present with an abnormal ECG and that 20 to $30 \%$ of patients will manifest a secondary cardiomyopathy $[4,5]$. In a recent study on out of hospital resuscitation for cardiac arrest (ROSC) survivors with significant ST-segment changes on ECG (mainly ST depression, QTc interval prolongation) performed immediately after ROSC - SAH was present in $25.0 \%$ of the patients [6]. The other series showed the prevalence of ST depression at least in $80 \%$ of SAH patients $[7,8]$.

Several mechanisms for the cardiac complications of SAH have been suggested. A generally accepted hypothesis is that the sympathetic stimulation induces catecholamine release in the myocardium leading to impaired systolic and diastolic function, repolarization abnormalities, and direct myocardial damage $[1,4,9]$. In addition, it has been reported that during the acute phase of $\mathrm{SAH}$, there is an increase in aortic wall stiffness leading to higher left ventricular pressures [9]. These mechanisms may explain the Takotsubo-like Cardiomyopathy (TCM) that occurred in our patient. Despite this single report of Takotsubo like cardiomyopathy presenting with SAH have appeared in the literature, few of them described presenting with clear-cut ST elevation on the ECG [10-12].

TCM most commonly occurs in in postmenopausal women $[13,14]$. Almost half of the cases are triggered by intense emotional or physical stress with release of catecholamines and intense sympathetic stimulation of the heart. The diagnostic criteria for TCM include the following: transient hypokinesis, akinesis, or dyskinesis (ballooning) in the left ventricular mid-wall segments with or without apical involvement; absence of obstructive coronary disease; new ECG abnormalities, elevation in cardiac troponin; and absence of pheochromocytoma and myocarditis. In general, TCM is a transient disorder that can be managed with supportive therapy such as angiotensin-converting-enzyme (ACE) inhibitors, beta-blockers, and diuretics $[13,15]$. But several cases have been mentioned in the literature of TCM complicating with Dressler Syndrome [16].

Our case represents a patient with $\mathrm{SAH}$ who appeared to be undergoing an acute ST-elevation myocardial infarction. Due to the presence of STEMI criteria on her ECG the patient was brought directly to the cath lab by the emergency ambulance service. At catheterization no coronary pathology was seen and TCM was diagnosed. The history obtained immediately after cath together with her sudden collapse strongly suggested the presence of SAH which was confirmed at CT. 
Citation: Davarashvili I, Jubeh R, Balkin J (2018) Subarachnoid Hemorrhage Masquerading as Takotsubo Cardiomyopathy. J Cardiovasc Dis Diagn 6: 320. doi: 10.4172/2329-9517.1000320

While other ST changes have been reported in the past the presence of ST elevation in SAH is extremely rare $[10,11]$. However, the presence of neurological symptoms even in a clear case of STEMI should prompt the performance of a CT scan prior to cardiac catheterization. In most hospitals this can be performed without delaying cardiac catheterization by more than a few minutes and may be critical to obtaining the correct diagnosis and obviate the need for cardiac catheterization and the administration of heparin which - as in this case - may worsen the SAH or affect the outcome.

\section{Conclusion}

We strongly advise that in patients presenting with acute MI and a history of any neurologic impairment or fall CT scan be performed prior to cardiac catheterization.

\section{References}

1. Naidech AM, Kreiter KT, Janjua N, Ostapkovich ND, Parra A, et al. (2005) Cardiac troponin elevation, cardiovascular morbidity, and outcome after subarachnoid hemorrhage. Circulation 112: 2851-2856.

2. van der Bilt IA, Hasan D, Vandertop WP, Wilde AA, Algra A, et al. (2009) Impact of cardiac complications on outcome after aneurismal subarachnoid hemorrhage: a meta-analysis. Neurology 72: 635-642.

3. Hravnak M, Frangiskakis JM, Crago EA, Chang $Y$, Tanabe $M$, et al. (2009) Elevated cardiac troponin 1 and relationship to persistence of electrocardiographic and echocardiographic abnormalities after aneurismal subarachnoid hemorrhage. Stroke 40: 3478-3484.

4. Banki N, Kopelnik A, Tung P, Lawton MT, Gress D, et al. (2006) Prospective analysis of prevalence, distribution, and rate of recovery of left ventricular systolic dysfunction in patients with subarachnoid hemorrhage. J Neurosurg 105: 15-20.

5. Kumai T, Inamasu J, Watanabe E, Sugimoto K, Hirose Y (2016) Differences between Takotsubo cardiomyopathy and reverse Takotsubo cardiomyopathy associated with subarachnoid hemorrhage. Int J Cardiol Heart Vasc 11: 99-103.

6. Kim YJ, Min SY, Lee DH, Lee BK, Jeung KW, et al. (2017) The role of postresuscitation electrocardiogram in patients with st-segment changes in the immediate post-cardiac arrest period. JACC Cardiovasc Interv 10: 451-459.

7. Mitsuma W, Ito M, Kodama M, Takano H, Tomita M, et al. (2011) Clinical and cardiac features of patients with subarachnoid haemorrhage presenting with out-of-hospital cardiac arrest. Resuscitation 82: 1294-1297.

8. Yamashina Y, Yagi T, Ishida A, Mibiki Y, Sato H, et al. (2015) Differentiating between comatose patients resuscitated from acute coronary syndromeassociated and subarachnoid hemorrhage-associated out-ofhospital cardiac arrest. J Cardiol 65: 508-513.

9. Papanikolaou J, Makris $D$, Karakitsos $D$, Saranteas $T$, Karabinis A, et al. (2012) Cardiac and central vascular functional alterations in the acute phase of aneurismal subarachnoid hemorrhage. Crit Care Med 40: 223-232.

10. Kadooka K, Hadeishi H, Kadooka K (2017) Delayed normalization of electrocardiograms in patients with Takotsubo cardiomyopathy due to aneurysmal subarachnoid hemorrhage. World Neurosurg 100: 467-473.

11. Elikowski W, Małek-Elikowska M, Kudliński B, Skrzywanek P, Smól S, et al (2016) ECG pattern in reverse takotshubo cardiomyopathy demonstrated in 5 cases with intracranial hemorrhage. Pol Merkur Lekarski 41: 136-140.

12. Madias JE (2016) What is the real prevalence of Takotsubo syndrome in patients admitted with aneurysmal subarachnoid hemorrhage? Clin Neurol Neurosurg 145: 104-105

13. Maiti A, Dhoble A (2017) Takotsubo cardiomyopathy. N Engl J Med 377: e24.

14. Rosenmann D, Balkin J, Butnaru A, Wanderman K, Klutstein M, et al. (2006) Transient left ventricular apical ballooning. Cardiology 105: 124-127.

15. Bybee KA, Kara T, Prasad A, Lerman A, Barsness GW, et al. (2004) Systematic review: transient left ventricular apical ballooning: a syndrome that mimics STsegment elevation myocardial infarction. Ann Intern Med 141: 858-865.

16. Davarashvili I, Hochberg-Klein S, Klein E (2017) Dressler's syndrome as complication of apical ballooning cardiomyopathy. Case Reports in Internal Medicine 4: 10-15 